\title{
Diagnostic and prognostic value of MCM3 and its interacting proteins in hepatocellular carcinoma
}

\author{
HONG-TAO LI ${ }^{1 *}$, BING WEI $^{2 *}$, ZHOU-QUAN LI ${ }^{*}$, XIAO WANG ${ }^{1,3 *}$, WEN-XIAN JIA ${ }^{4}$, \\ YAN-ZHEN XU ${ }^{1}$, JIA-YI LIU ${ }^{3,5}$, MENG-NAN SHAO ${ }^{1}$, SUI-XIA CHEN ${ }^{1}$, NAN-FANG MO ${ }^{1}$, \\ DONG ZHAO $^{1}$, WEN-PU ZUO ${ }^{6}$, JIAN QIN ${ }^{7}$, PING LI $^{3,5}$, QIN-LE ZHANG $^{8}$ and XIAO-LI YANG ${ }^{1}$
}

${ }^{1}$ Scientific Research Center; ${ }^{2}$ College of International Education, Guilin Medical University, Guilin, Guangxi 541100;

${ }^{3}$ Department of Pathology, The First Affiliated Hospital; ${ }^{4}$ College of Pharmacy; ${ }^{5}$ College and Hospital of Stomatology;

${ }^{6}$ Medical Scientific Research Center; ${ }^{7}$ School of Public Health, Guangxi Medical University, Nanning,

Guangxi 530021; ${ }^{8}$ Genetic and Metabolic Central Laboratory, The Maternal and Children

Health Hospital of Guangxi, Nanning, Guangxi 530005, P.R. China

Received October 2, 2019; Accepted June 8, 2020

DOI: $10.3892 / 01.2020 .12171$

\begin{abstract}
Aberrant DNA replication is one of the driving forces behind oncogenesis. Furthermore, minichromosome maintenance complex component 3 (MCM3) serves an essential role in DNA replication. Therefore, in the present study, the diagnostic and prognostic value of MCM3 and its interacting proteins in hepatocellular carcinoma (HCC) were investigated. By utilizing The Cancer Genome Atlas (TCGA) database, global MCM3 mRNA levels were assessed in HCC and normal liver tissues. Its effects were further analyzed by reverse transcription-quantitative PCR (RT-qPCR), western
\end{abstract}

Correspondence to: Professor Xiao-Li Yang, Scientific Research Center, Guilin Medical University, 1 Zhiyuan Road, Guilin, Guangxi 541100, P.R. China

E-mail: cncsyxl@126.com

*Contributed equally

Abbreviations: MCM3, minichromosome maintenance complex component 3; HCC, hepatocellular carcinoma; TCGA, The Cancer Genome Atlas; RT-qPCR, reverse transcription-quantitative PCR; ROC, receiver operating characteristic; AFP, $\alpha$-fetoprotein; ALT, alanine aminotransferase; AST, aspartate transaminase; PPI, protein-protein interaction; STRING, Search Tool for the Retrieval of Interacting Genes; MCODE, Molecular Complex Detection; OS, overall survival; RFS, recurrence-free survival; MF, molecular functions; CHK1, checkpoint kinase 1; DHX9, DEAH (Asp-Glu-Ala-His) box helicase 9; DDR, DNA damage response; AUC, area under the curve; RSEM, RNA-Seq by Expectation-Maximization; GO, Gene Ontology; KEGG, Kyoto Encyclopedia of Genes and Genomes; E-S grade, pathological Edmondson-Steiner grade

Key words: hepatocellular carcinoma, minichromosome maintenance complex component 3, diagnostic ability, multi-gene diagnosis, biomarker blotting and immunohistochemistry in 78 paired HCC and adjacent tissues. Functional and pathway enrichment analyses were performed using the Search Tool for the Retrieval of Interacting Genes database. The expression levels of proteins that interact with MCM3 were also analyzed using the TCGA database and RT-qPCR. Finally, algorithms combining receiver operating characteristic (ROC) curves were constructed using binary logistic regression using the TCGA results. Increased MCM3 mRNA expression with high $\alpha$-fetoprotein levels and advanced Edmondson-Steiner grade were found to be characteristic of HCC. Survival analysis revealed that high MCM3 expression was associated with poor outcomes in patients with HCC. In addition, MCM3 protein expression was associated with increased tumor invasion in HCC tissues. MCM3 and its interacting proteins were found to be primarily involved in DNA replication, cell cycle and a number of binding processes. Algorithms combining ROCs of MCM3 and its interacting proteins were found to have improved HCC diagnosis ability compared with MCM3 and other individual diagnostic markers. In conclusion, MCM3 appears to be a promising diagnostic biomarker for HCC. Additionally, the present study provides a basis for the multi-gene diagnosis of HCC using MCM3.

\section{Introduction}

Minichromosome maintenance complex component (MCM)3, one of the highly conserved MCMs, is involved in prokaryotic and eukaryotic genome replication (1). MCM forms a hexameric protein complex, which is a key component of the pre-replication complex. This complex is involved in the formation of the replication fork and in the recruitment of other DNA replication proteins (2). MCM3 is a subunit/component of the hexameric protein complex that consists of MCM2-7 and directly interacts with MCM5 (3). MCM3 is essential for the initiation of DNA replication and is involved in ensuring that DNA replication is initiated precisely once per cell cycle (4). The initiation of DNA replication and cell cycle 
progression is triggered by acetylation of MCM3 (4), and cells lacking MCM3 fail to proceed into $\mathrm{S}$ phase and proliferate (5). Furthermore, MCM3 is a point of direct contact between Kelch-like ECH-associated protein 1 (KEAP1; a substrate adaptor protein for a cullin-3-based E3 ubiquitin ligase) and the MCM2-7 hexamer. KEAP1-mediated MCM3 ubiquitylation may also impact helicase activation (6).

Hepatocellular carcinoma (HCC), a common malignant tumor, accounts for $90 \%$ of primary liver malignancies (7). $\mathrm{HCC}$ is the second most common cause of cancer-associated mortality worldwide and this proportion continues to increase (8). In the United States alone, annual HCC-related deaths have doubled from 5,112 in 1999 to 11,073 in 2016 (9). A high incidence of HCC has also been noted in China (10). Hepatitis virus infection (HBV or HCV), cirrhosis, HIV co-infection, alcoholism, obesity, aflatoxin B1 intake and inherited factors are associated with increased incidence of HCC $(7-8,10)$. Current treatments for HCC, including surgical resection, liver transplantation and occasionally ablative therapies, only provide limited benefits. Survival of patients with HCC is limited even following liver excision or liver transplantation (8). The disease is refractory to classic chemotherapy and is unsuitable for radiation treatment due to the chance of developing liver toxicity $(7-8,10)$. Due to the difficulties associated with early diagnosis and the high incidence of tumor recurrence, identification of novel HCC treatment methods is required to improve patient outcomes.

MCM proteins, which are overexpressed in various neoplasms, can be used as proliferation markers to analyze the behavior of diverse neoplasms $(11,12)$. A previous study has demonstrated that overexpression of MCM3 enhances anchorage-independent cell growth, cell migration and invasion abilities of medulloblastoma cells (13). These results suggest that MCM3 is likely to be associated with tumor migration and invasion. Increased MCM3 expression has also been observed in melanoma, prostate cancer, cervical squamous cell carcinoma and salivary gland tumors $(1,5,14)$. These studies indicate that MCM3 may be a potential proliferation marker in the diagnosis of certain tumors $(1,5,13,14)$. In certain tumors, MCM3 may also be detected in non-proliferating cells, which indicates their readiness to enter the cell cycle (15).

There is limited research regarding MCM3 in HCC. Therefore, the association between MCM3 and clinical features of HCC remains unclear. The present study assessed the effect of MCM3 in HCC. MCM3 expression was analyzed using The Cancer Genome Atlas (TCGA) database. mRNA and protein expression levels were detected in $\mathrm{HCC}$ and paired adjacent tissues. Additionally, the association between MCM3 expression and the clinicopathological features of patients with HCC were evaluated, including common diagnostic marker AFP and noninvasive liver function parameters ALT and AST, which are commonly tested in clinical practice to indicate prognosis $(16,17)$. Subsequently, functional and pathway enrichment analyses were carried out and a protein-protein interaction (PPI) network of MCM3 was established. The present study bridges the gap in understanding the underlying molecular mechanisms of MCM3 and its interacting proteins in HCC. Finally, the expression of the proteins that interact with MCM3, including MCM family proteins and non-MCM family proteins, were analyzed in the context of HCC.
Algorithms combining the receiver operating characteristic (ROC) curves of MCM3 and its interaction partners were constructed to improve the diagnosis of HCC when compared with MCM3 alone.

\section{Materials and methods}

Patients and HCC specimen. A total of 78 patients (age range, 28-68 years; median age, 45 years) with HCC who were diagnosed according to the Chinese primary liver cancer guidelines (18) and treated at the Department of Hepatobiliary Pancreatic Surgery of the Affiliated Hospital of Guilin Medical University (Guilin, P.R. China) between January 2017 and August 2018 were prospectively recruited in the present study. All patients had not received any antitumor therapy prior to surgery. Surgical indications of these patients met the following criteria based on the Chinese primary liver cancer guidelines (18): i) Patients with good liver function reserve and HCC staging Ia, Ib and IIa; ii) patients with HCC staging IIb and IIIa who have $<3$ tumor nodules; and iii) patients with HCC staging IIb and IIIa that meet particular conditions, including: a) Patients have $>3$ tumor nodules that are localized in the same segment or lobe, or if radiofrequency ablation can be performed for some lesions during surgery; b) the tumor is localized in one lobe and the tumor emboli are expected to be completely resected during surgery; c) patients that have obstructive jaundice because of tumor emboli in the bile duct and the intrahepatic tumors are resectable; and d) patients with portal lymph node metastases, intraoperative lymph node dissection or postoperative external radiation therapy. HCC samples, including tumor tissue and adjacent tissues ( $\geq 2 \mathrm{~cm}$ distance from the tumor margin) were then collected during radical resection or partial resection. The demographic and clinicopathological characteristics, including age, sex, smoking, drinking, Hepatitis B virus infection, $\alpha$-fetoprotein (AFP), alanine minotransferase (ALT), aspartate transaminase (AST), tumor size and pathological Edmondson-Steiner (E-S) grade (19), were also obtained. The present study was approved by the Ethics Committee of The Affiliated Hospital of Guilin Medical University and written informed consent was obtained from all patients.

Data collection and analysis from TCGA. RNA-seq data quantified using RNA-Seq by Expectation-Maximization (RSEM) were downloaded from TCGA (https://tcga.xenahubs.net). In particular, the level-3 data were downloaded from TCGA data coordination center. In order to acquire TCGA data comparable to the subject of the present research, only patients with HCC were included in the analysis $(n=363)$, and were paired with non-HCC (normal liver) samples for statistical analysis $(n=50)$. In addition, data regarding clinical features of patients for all downloaded datasets (LIHC_clinicalMatrix) were collected.

Reverse transcription-quantitative PCR (RT- $q P C R)$. RT-qPCR was used to determine mRNA expression levels of different genes in $78 \mathrm{HCC}$ tissue samples. Total RNA from HCC specimens was isolated using TRIzol reagent (Invitrogen; Thermo Fisher Scientific, Inc.) according to the manufacturer's protocol. Total RNA (1 ug) was reverse transcribed to cDNA using a two-step RT Kit (Takara Biotechnology Co., Ltd.) according to the manufacturer's protocol. Complementary 
Table I. Primers utilized for reverse transcription-quantitative PCR amplification.

\begin{tabular}{lll}
\hline Gene & Upstream primer sequence $\left(5^{\prime}-3^{\prime}\right)$ & Downstream primer sequence $\left(5^{\prime}-3^{\prime}\right)$ \\
\hline MCM2 & ATCTACGCCAAGGAGAGGGT & GTAATGGGGATGCTGCCTGT \\
MCM3 & TGGCCTCCATTGATGCTACC & GGACGACTTTGGGACGAACT \\
MCM5 & TCATCTCCAAGAGCATCGCC & CCTCGGCGAGTAAGTCCATC \\
CHK1 & AATGCTCGCTGGAGAATTGC & CACCACCTGAAGTGACTCGG \\
DHX9 & GCCAATTTCTGGCCAAAGCA & CGAGGCTCAATGGGGAGTTT \\
-actin & CAGGCACCAGGGCGTGAT & TAGCAACGTACATGGCTGGG
\end{tabular}

MCM, minichromosome maintenance complex component; CHK1, checkpoint kinase 1; DHX9, DEAH (Asp-Glu-Ala-His) box helicase 9.

DNA was amplified using the StepOnePlus system (Applied Biosystems; Thermo Fisher Scientific, Inc.) with SYBR Green master mix [Roche Diagnostics (Shanghai) Co., Ltd.]. The RT-qPCR conditions used were as follows: Initiation at $95^{\circ} \mathrm{C}$ for $10 \mathrm{~min}$, followed by 40 cycles of $95^{\circ} \mathrm{C}$ for $15 \mathrm{sec}$ and $60^{\circ} \mathrm{C}$ for $1 \mathrm{~min}$, final extension at $60^{\circ} \mathrm{C}$ for $10 \mathrm{~min}$. mRNA expression levels were calculated using the $2^{-\Delta \Delta \mathrm{Cq}}$ method (20). $\beta$-actin was used as an internal control. The primers used for RT-qPCR amplification are shown in Table I.

Western blotting. Total protein was extracted from tissue $(5 \mathrm{mg})$ using $300 \mu \mathrm{l}$ ice-cold RIPA lysis buffer (Beyotime Institute of Biotechnology) with proteinase inhibitor and homogenized using an electric homogenizer. Samples were centrifuged at $12,000 \mathrm{rpm}$ for $20 \mathrm{~min}$ at $4^{\circ} \mathrm{C}$ and the supernatant was collected. Protein concentration was determined using a BCA assay (Beijing Leagene Biotech, Co., Ltd.). Total protein was mixed with $5 \mathrm{X}$ loading buffer mix and boiled at $100^{\circ} \mathrm{C}$ for $5 \mathrm{~min}$. Equal amounts of total protein $(20 \mu \mathrm{g} /$ lane $)$ were separated on a $10 \%$ SDS-PAGE gel and transferred to a PVDF membrane using a Bio-Rad SemiDry apparatus. The membranes were blocked in TBS + Tween 20 (TBST; 0.1\% Tween 20) containing 5\% BSA (Beijing Solarbio Science \& Technology Co., Ltd.) at room temperature for $1 \mathrm{~h}$. Anti-MCM3 primary antibody (diluted in TBST; 1:1,000; cat no. ab128923; Abcam) and the loading control anti- $\beta$-actin antibody (diluted in TBST; 1:4,000, cat. no. HRP-60008; ProteinTech Group, Inc.) were added to the membranes at $4^{\circ} \mathrm{C}$ overnight. The membranes were rinsed three times for $5 \mathrm{~min}$ with TBST and then incubated with HRP-conjugated secondary antibody (diluted in TBST; 1:3,000; cat. no. SA00001-2; ProteinTech Group, Inc.) for $1 \mathrm{~h}$ at room temperature. The membranes were rinsed three times for 5 min with TBST and protein bands were visualized using the chemiluminescent substrate BeyoECL Plus kit (Beyotime Institute of Biotechnology). The FluorChem HD2 chemiluminescence system (ProteinSimple) was used for protein visualization. Protein expression was semi-quantified using ImageJ software (version 1.52a; National Institutes of Health) with $\beta$-actin as the loading control.

Immunohistochemistry (IHC). All tissues were fixed in 4\% paraformaldehyde for $24 \mathrm{~h}$ at room temperature, embedded in paraffin, and sliced into $4-\mu \mathrm{m}$ sections. Embedded sections were deparaffinized with xylene and rehydrated with a descending ethanol series (100, 95, 90 and 85\%), followed by antigen retrieval in citrate acid buffer for 15 min using an autoclave at $121^{\circ} \mathrm{C}$. Subsequently, protein expression was analyzed using the SP-9000 two-step immunohistochemical staining kit (OriGene Technologies, Inc.) according to the manufacturer's protocol. Endogenous peroxidase activity was blocked with hydrogen peroxide at room temperature for $15 \mathrm{~min}$. After a 10 -min incubation with goat serum at room temperature, sections were incubated with anti-MCM3 primary antibody (dilution in PBS; 1:1,000; cat. no. ab128923; Abcam) overnight at $4^{\circ} \mathrm{C}$ in a humidified chamber. Negative controls were incubated with PBS instead of the primary antibody. After washing with PBS, samples were incubated with the biotinylated secondary antibody at room temperature for $15 \mathrm{~min}$. Sections were incubated with horseradish peroxidase at room temperature for $15 \mathrm{~min}$ and developed in 3,3'-diaminobenzidine peroxidase substrate solution. Finally, sections were counterstained with hematoxylin at room temperature for $5 \mathrm{~min}$, dehydrated and mounted in resin blocks.

Two independent pathologists evaluated the degree of IHC staining under a light microscope. In each sample, $\geq 1,000$ cells were counted and 10 high-power fields (magnification, $\mathrm{x} 400$ ) were analyzed. The average number was considered for the whole sample. The average labelling index of MCM3 from 10 randomly selected high-power fields was recorded as follows: i) 0 , no staining, or faint staining intensity in $<10 \%$ of cells; ii) $1+$, faint nuclear/cytoplasmic staining in $\geq 10 \%$ of cells; iii) $2+$, moderate and incomplete nuclear staining in $\geq 10 \%$ of cells; and iv) $3+$, strong nuclear staining in $\geq 10 \%$ of cells (21). Specimens exhibiting immunostaining of $3+$ were defined as high expression of MCM3; expression levels of $1+$ or $2+$ were defined as low expression, and 0 was defined as negative expression.

PPInetwork construction and module analysis. The functional interactions between proteins can provide context in molecular mechanisms of MCM3 and its interacting proteins in the development of HCC. In the present study, a PPI network consisting of MCM3 and its interacting proteins was constructed using the Search Tool for the Retrieval of Interacting Genes (STRING) software tool (version 11.0; http://string-db.org). Cytoscape v17 software (www.cytoscape.org) with Molecular Complex Detection (MCODE; version 1.6.1) (22) was used to visualize and screen modules of the PPI network as previously described (23).

Functional and pathway enrichment analysis. MCM3 and its interacting proteins were used to perform Gene Ontology 
A
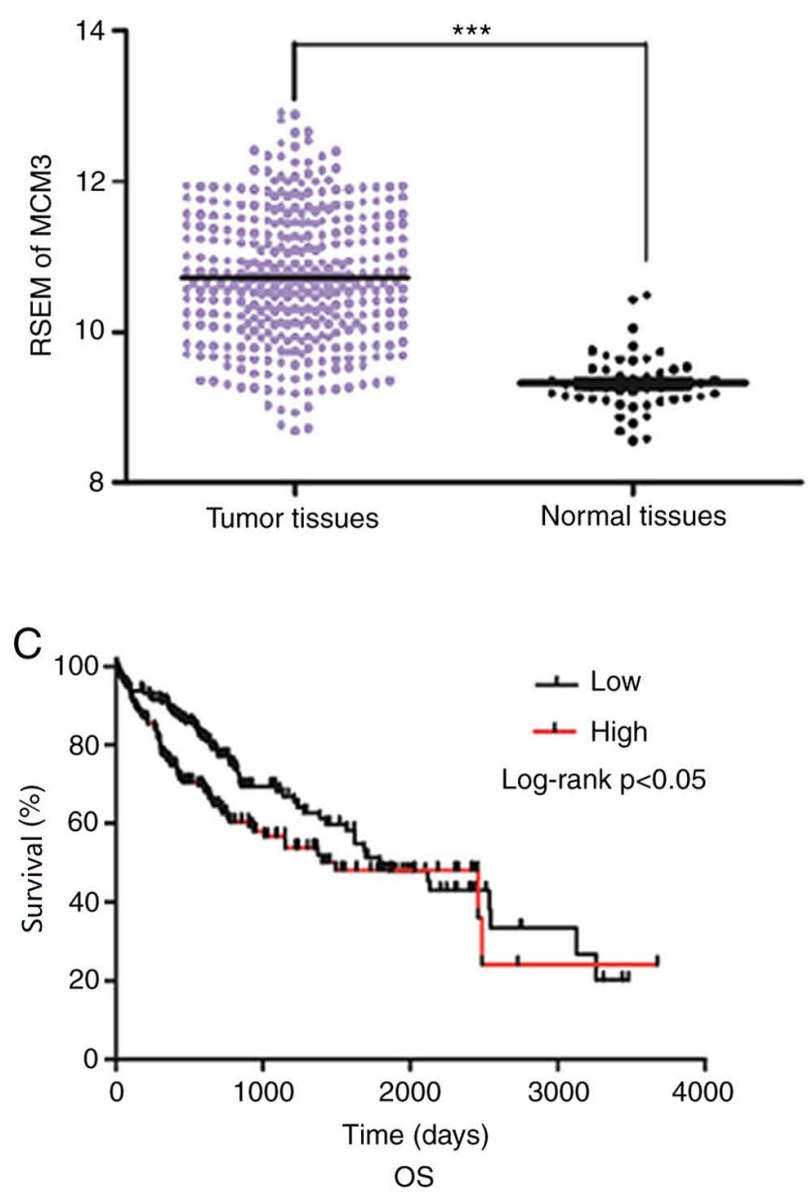

B

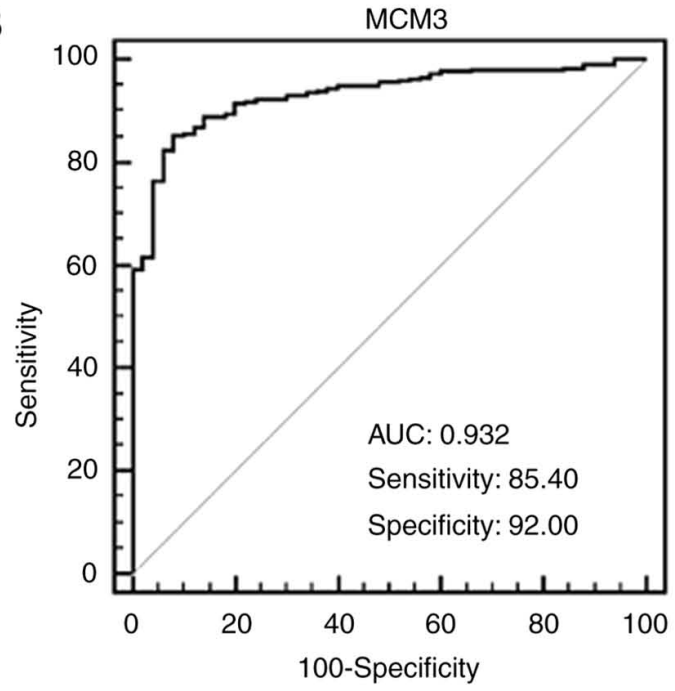

$\mathrm{D}$

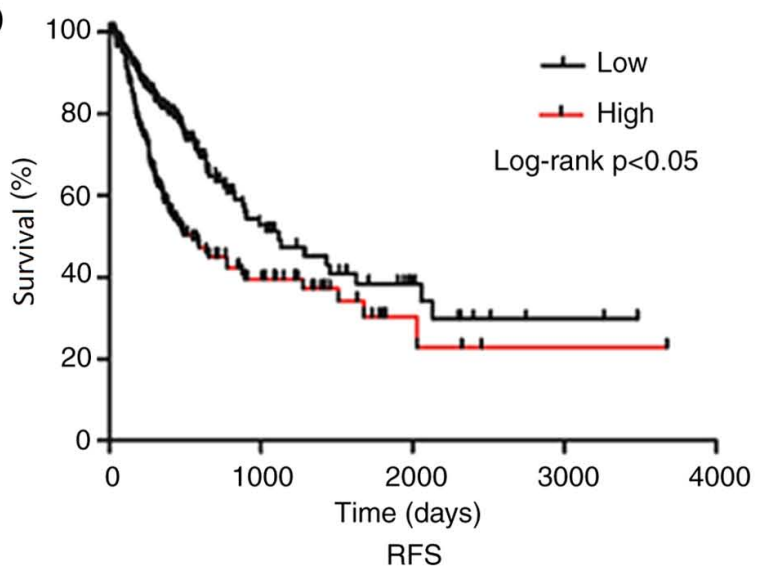

Figure 1. Data mining of MCM3 expression from The Cancer Genome Atlas database. (A) MCM3 mRNA expression in HCC tissues and normal liver tissues. mRNA was normalized by RSEM. Higher MCM3 mRNA expression was found in HCC tissues compared with in normal liver tissues (P<0.05). (B) Receiver operating characteristic curve of MCM3 for diagnosis of HCC. (C) OS in patients with high expression levels of MCM3 compared with in patients with low expression levels of MCM3. (D) RFS in patients with high expression levels of MCM3 compared with in patients with low expression levels of MCM3. ${ }^{*}{ }^{* *} \mathrm{P}<0.05$. MCM3, minichromosome maintenance complex component 3; HCC, hepatocellular carcinoma; RSEM, RNA-Seq by Expectation-Maximization; AUC, area under the curve; OS, Overall survival; RFS, recurrence-free survival.

(GO; http://www.geneontology.org) and Kyoto Encyclopedia of Genes and Genomes (KEGG; http://www.genome.jp/kegg) pathway enrichment analysis in STRING. $\mathrm{P}<0.05$ was set as the cut-off criterion.

Statistical analysis. Statistical analysis was performed using the SPSS software (version 22.0; IBM Corp.). Data are presented as the mean \pm standard deviation. Unpaired comparisons between $363 \mathrm{HCC}$ tissues and 50 normal tissues were analyzed using Student's unpaired t-test and Welch t-test. Comparisons between two paired groups (78 HCC tissues vs. paired adjacent tissues) were conducted using Wilcoxon signed-rank test for IHC data and Student's paired t-test for RT-qPCR results. The association between MCM3 expression and clinicopathological factors in patients with HCC was determined using $\chi^{2}$ test with Fisher's exact test. The ROC curves and the area under the curve (AUC) were used to evaluate the diagnostic value of different genes in HCC. Pairwise comparisons of ROC curves were conducted using MedCalc (version 9.2.0.1; MedCalc Software Ltd.) and the best cut-off value for each gene was defined as the point with maximum Youden index (sensitivity + specificity-1) on the ROC curve. Based on the mRNA data (RSEM) extracted from TCGA liver hepatocellular carcinoma dataset, binary logistic regression analysis was used to generate algorithms combining ROCs of MCM3 and its interacting proteins. Enrichment analysis was performed in the STRING database. False discovery rate $<0.05$ was considered statistically significant. Overall survival (OS) and recurrence-free survival (RFS) time were stratified according to the median expression levels of RSEM of different genes (high and low). Survival analysis was conducted using Kaplan-Meier analysis with a log-rank test. $\mathrm{P}<0.05$ was considered to indicate a statistically significant difference.

\section{Results}

Analyses of MCM3 using the TCGA database. The MCM3 mRNA expression levels in 413 selected tissues (363 tumor tissues and 50 normal tissues) were obtained from TCGA. Increased MCM3 expression was observed in the tumor tissues (Fig. 1A). When the associations between MCM3 and clinical 
Table II. Association between MCM3 expression levels and clinicopathologic characteristics in hepatocellular carcinoma in The Cancer Genome Atlas dataset $(n=363)$.

\begin{tabular}{|c|c|c|c|}
\hline Clinical features & Cases, $\mathrm{n}$ & $\begin{array}{c}\text { MCM3 levels } \\
(\mathrm{RSEM} ; \text { mean } \pm \mathrm{SD})\end{array}$ & P-value \\
\hline \multicolumn{4}{|l|}{ Sample } \\
\hline LIHC & 363 & $10.7220 \pm 0.8776$ & \multirow[t]{2}{*}{$<0.001$} \\
\hline Normal & 50 & $9.3221 \pm 0.3847$ & \\
\hline \multicolumn{4}{|l|}{$\begin{array}{l}\text { Age at diagnosis, } \\
\text { years }\end{array}$} \\
\hline$\leq 45$ & 48 & $10.9396 \pm 0.9240$ & \multirow[t]{3}{*}{0.065} \\
\hline$>45$ & 314 & $10.6881 \pm 0.8683$ & \\
\hline Unknown & 1 & & \\
\hline \multicolumn{4}{|l|}{ Sex } \\
\hline Female & 117 & $10.8264 \pm 0.8170$ & \multirow[t]{2}{*}{0.118} \\
\hline Male & 246 & $10.6724 \pm 0.9024$ & \\
\hline \multicolumn{4}{|l|}{$\begin{array}{l}\text { AFP in serum, } \\
\mathrm{ng} / \mathrm{ml}\end{array}$} \\
\hline$\leq 20$ & 143 & $10.4980 \pm 0.8607$ & \multirow[t]{3}{*}{$<0.001$} \\
\hline$>20$ & 129 & $10.9507 \pm 0.8032$ & \\
\hline Unknown & 91 & & \\
\hline \multicolumn{4}{|l|}{ E-S grade } \\
\hline I-II & 225 & $10.5271 \pm 0.8640$ & \multirow[t]{3}{*}{$<0.001$} \\
\hline III-IV & 133 & $11.0550 \pm 0.8095$ & \\
\hline Unknown & 5 & & \\
\hline \multicolumn{4}{|l|}{$\begin{array}{l}\text { Child-Pugh } \\
\text { classification }\end{array}$} \\
\hline A & 213 & $10.6595 \pm 0.8948$ & \multirow[t]{4}{*}{0.806} \\
\hline $\mathrm{B}$ & 21 & $10.6102 \pm 0.6849$ & \\
\hline $\mathrm{C}$ & 1 & & \\
\hline Unknown & 128 & & \\
\hline \multicolumn{4}{|l|}{ Lymph node } \\
\hline N0 & 246 & $10.7852 \pm 0.8700$ & \multirow[t]{3}{*}{0.441} \\
\hline N1 & 3 & $11.1746 \pm 0.4966$ & \\
\hline Unknown & 114 & & \\
\hline \multicolumn{4}{|l|}{ Metastasis } \\
\hline M0 & 260 & $10.7999 \pm 0.8767$ & \multirow[t]{3}{*}{0.432} \\
\hline M1 & 4 & $10.4529 \pm 0.7069$ & \\
\hline Unknown & 99 & & \\
\hline \multicolumn{4}{|l|}{ HBsAg infection } \\
\hline Yes & 137 & $10.8366 \pm 0.9352$ & \\
\hline No & 0 & & \\
\hline Unknown & 226 & & \\
\hline
\end{tabular}

LIHC, liver hepatocellular carcinoma; RSEM, RNA-Seq by Expectation-Maximization; MCM3, minichromosome maintenance complex component 3; AFP, $\alpha$-fetoprotein; E-S, pathological Edmondson-Steiner; HBsAg, hepatitis B surface antigen.

features, including age, sex, AFP, E-S grade, Child-Pugh classification (24), hepatitis B surface antigen infection and lymph node metastasis, were evaluated in HCC, elevated MCM3 expression was identified to be associated with high AFP levels, as well as advanced E-S grade (Table II). However, no association was observed between MCM3 expression and other clinical factors. In addition, Kaplan-Meier analysis indicated that patients with high MCM3 expression had poorer OS and RFS rates than patients with low MCM3 expression (Fig. 1C and D).

To further assess the diagnostic utility of MCM3 in HCC, a ROC curve with an AUC of 0.932 was constructed by plotting sensitivity vs. specificity. At a cut-off point of 9.757, which was determined using the Youden's index, the sensitivity and specificity were 85.40 and $92.00 \%$, respectively (Fig. 1B).

MCM3 expression in HCC and adjacent tissues. High MCM3 expression at the mRNA and protein levels in HCC tissues was observed compared with in paired adjacent tissues (Fig. 2). The RT-qPCR results indicated that MCM3 mRNA expression was higher in the HCC tissues than in the adjacent tissues (Fig. 2A). Immunoblotting and IHC demonstrated increased MCM3 expression in $\mathrm{HCC}$ at the protein level (Fig. 2B and C). Interestingly, MCM3 proteins were primarily observed in the nuclei of tumor cells (Fig. 2C). The statistical analysis of IHC data revealed that there was a significant difference between HCC and adjacent normal tissues, with MCM3 being highly expressed in 37 (47.4\%) of the $78 \mathrm{HCC}$ tissues, whereas there were only $13(16.7 \%)$ tissues with high MCM3 expression among the adjacent normal tissues (Table III).

Association between MCM3 expression and clinical features of patients with HCC. The analysis of the association between MCM3 expression and the clinical features of the respective patients revealed that enhanced MCM3 expression was associated with invasiveness of the tumor cells (Table IV). However, there was no association identified between MCM3 expression and other clinical features, such as age, sex, smoking, drinking, HBsAg infection, AFP, E-S grade, ALT, AST and metastasis, in patients with HCC (Table IV).

Construction of a PPI network and module analysis. A PPI network of MCM3 and the proteins that interact with it, including MCM2-7 and other genes, was generated with STRING and visualized using Cytoscape (Fig. 3A). MCM4/6/7 formed a core subcomplex, while MCM3 was associated with both MCM2 and MCM5 and served a regulatory role in the MCM complex (25). A significant module was obtained from the PPI network by applying MCODE in Cytoscape (Fig. 3B). The module containing MCM3 was associated with 'DNA replication', 'cell cycle', 'nucleoplasm' and 'binding' $(\mathrm{P}<0.05$, Fig. 3C).

GO functional enrichment analysis and KEGG pathway enrichment analysis. The significant terms of GO and KEGG enrichment analysis obtained using STRING are shown in Table V. MCM3 and its interacting proteins were mainly involved in biological processes, such as 'DNA replication', 'cell cycle', 'cell cycle processes', and 'chromosome organization'. The molecular functions (MFs) mainly included 'helicase activity' and numerous binding processes, including 'ATP binding', 'DNA binding', 'heterocyclic compound binding', 'organic cyclic compound binding' and 'chromatin binding'. Cell component annotations suggested that the 
Table III. Expression levels of MCM3 in HCC and adjacent tissues.

\begin{tabular}{lccc}
\hline MCM3 levels & Labelling index & HCC tissues, $n(\%)$ & Adjacent tissues, $(\%)$ \\
\hline Negative expression & 0 & $8(10.3)$ & $16(20.5)$ \\
Low expression & $1+$ & $11(14.1)$ & $25(32.0)$ \\
& $2+$ & $22(28.2)$ & $24(30.8)$ \\
High expression & $3+$ & $37(47.4)$ & $13(16.7)$ \\
\hline
\end{tabular}

0 , no or faint staining intensity in $<10 \%$ of cells; $1+$, faint nuclear/cytoplasmic staining in $\geq 10 \%$ of cells; $2+$, moderate and incomplete nuclear staining in $\geq 10 \%$ of cells; $3+$, strong nuclear staining in $\geq 10 \%$ of cells; MCM3, minichromosome maintenance complex component 3 ; HCC, hepatocellular carcinoma.
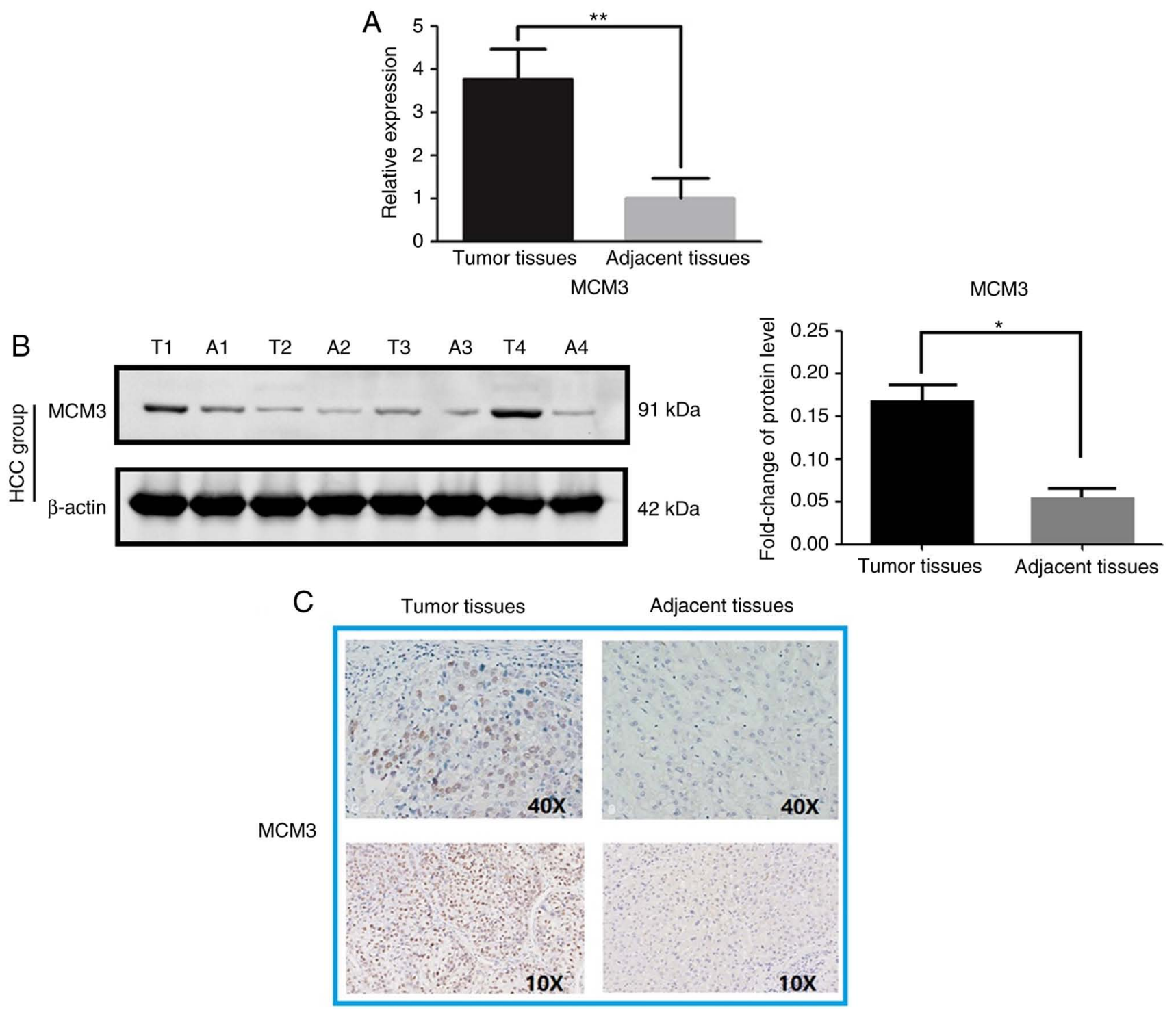

Figure 2. MCM3 expression in HCC tissues and the adjacent tissues. (A) Relative mRNA levels of MCM3 in HCC tissues and the corresponding adjacent tissues. (B) Protein levels of MCM3 in HCC tissues and the adjacent tissues detected by western blotting. (C) Immunohistochemical staining of MCM3 in HCC tissues and the adjacent tissues. T, tumor tissue; A, adjacent tissue; MCM3, minichromosome maintenance complex component 3; HCC, hepatocellular carcinoma. ${ }^{*} \mathrm{P}<0.05,{ }^{* *} \mathrm{P}<0.01$.

proteins were enriched predominantly in the 'nucleoplasm' and 'protein-containing complex'. KEGG enrichment analysis suggested that MCM3 and its interacting proteins were associated with the 'cell cycle' and 'DNA replication'.
Expression levels of the MCM3 interactome [MCM2, MCM5, checkpoint kinase 1 (CHKI), and DEAH (Asp-Glu-Ala-His) box helicase 9 (DHX9)] in HCC. TCGA and RT-qPCR analysis revealed significantly higher expression levels of MCM2, 
Table IV. Association between MCM3 expression levels and clinicopathological characteristics in hepatocellular carcinoma $(n=78)$.

\begin{tabular}{|c|c|c|c|c|}
\hline \multirow[b]{2}{*}{ Clinical features } & \multirow[b]{2}{*}{ Cases, $\mathrm{n}$} & \multicolumn{2}{|c|}{ MCM3 levels } & \multirow[b]{2}{*}{ P-value } \\
\hline & & $\begin{array}{c}\text { Low/Negative, } \\
n(n=41)\end{array}$ & $\begin{array}{c}\text { High, } \\
\text { n }(n=37)\end{array}$ & \\
\hline \multicolumn{5}{|l|}{ Age, years } \\
\hline$\leq 45$ & 31 & 17 & 14 & 0.819 \\
\hline$>45$ & 47 & 24 & 23 & \\
\hline \multicolumn{5}{|l|}{ Sex } \\
\hline Male & 55 & 31 & 24 & 0.330 \\
\hline Female & 23 & 10 & 13 & \\
\hline \multicolumn{5}{|l|}{ Smoking } \\
\hline Yes & 32 & 19 & 13 & 0.362 \\
\hline No & 46 & 22 & 24 & \\
\hline \multicolumn{5}{|l|}{ Drinking } \\
\hline Yes & 36 & 19 & 17 & 1.000 \\
\hline No & 42 & 22 & 20 & \\
\hline \multicolumn{5}{|l|}{ HBsAg infection } \\
\hline Yes & 54 & 28 & 26 & 1.000 \\
\hline No & 24 & 13 & 11 & \\
\hline \multicolumn{5}{|l|}{ AFP, ng/ml } \\
\hline$\leq 20$ & 26 & 14 & 12 & 1.000 \\
\hline$>20$ & 52 & 27 & 25 & \\
\hline \multicolumn{5}{|l|}{ ALT, U/1 } \\
\hline$\leq 40$ & 41 & 23 & 18 & 0.650 \\
\hline$>40$ & 37 & 18 & 19 & \\
\hline \multicolumn{5}{|l|}{ AST, U/l } \\
\hline$\leq 40$ & 37 & 20 & 17 & 0.824 \\
\hline$>40$ & 41 & 21 & 20 & \\
\hline \multicolumn{5}{|l|}{ E-S grade } \\
\hline I-II & 33 & 17 & 16 & 1.000 \\
\hline III-IV & 45 & 24 & 21 & \\
\hline \multicolumn{5}{|l|}{ Tumor size $(\mathrm{cm})$} \\
\hline$\leq 5$ & 32 & 18 & 14 & 0.649 \\
\hline$>5$ & 46 & 23 & 23 & \\
\hline \multicolumn{5}{|l|}{ Metastasis } \\
\hline Yes & 25 & 14 & 11 & 0.809 \\
\hline No & 53 & 27 & 26 & \\
\hline \multicolumn{5}{|l|}{ Invasion } \\
\hline Yes & 51 & 22 & 29 & 0.032 \\
\hline No & 27 & 19 & 8 & \\
\hline
\end{tabular}

MCM3, minichromosome maintenance complex component 3; HBsAg, hepatitis B surface antigen; AFP, $\alpha$-fetoprotein; ALT, alanine aminotransferase; AST, aspartate transaminase; E-S, pathological Edmondson-Steiner.

MCM5, CHK1 and DHX9 in HCC tissues compared with in normal or adjacent tissues (Fig. 4A and B).

Impact of MCM3 interactome (MCM2, MCM5, CHK1 and DHX9) in patients with HCC. Based on the data from TCGA, the area under the curve (AUC) of HCC samples expressing MCM2, MCM5, CHK1 and DHX9 was 0.930, 0.895, 0.883 and 0.727 , respectively, according to RSEM analysis (Table VI). The sensibility and specificity of these genes in indicating HCC diagnosis are shown in Table VI. Furthermore, high expression levels of MCM2 and CHK1 were associated with poor OS and RFS (Fig. 4C and D).

In order to improve the HCC diagnosis efficiency, three combined models were generated. The ROC curve of model 1, which had the highest specificity of any of the models, combined the utility of CHK1 and MCM3 (Fig. 5A). The sensitivity and specificity of model 1 were 88.15 and $100 \%$, respectively (Table VI). Model 2, combining the utility of DHX9 and MCM3, had a sensitivity and specificity of 99.17 and $94.00 \%$, respectively, and its sensitivity was the highest of the three models (Table VI; Fig. 5B). Model 3 combined the utility of MCM2, MCM3 and MCM5, and had a sensitivity and specificity of 98.35 and $94.00 \%$, respectively (Table VI; Fig. 5C). The AUCs of models 1, 2 and 3 were $0.975,0.967$ and 0.989 , respectively, which were higher than those of MCM3 or any of its interacting proteins alone (Table VI; Fig. 5). The specific algorithm of each model is indicated in Table VI.

\section{Discussion}

Studies have indicated that MCM3 is overexpressed in certain carcinomas, such as melanoma, prostate cancer, cervical squamous cell carcinoma and salivary gland tumors $(1,5,12)$. However, little research has been conducted on MCM3 in HCC. Recent studies have only focused on the prognostic or diagnostic value of MCM3 in $\operatorname{HCC}(26,27)$, whereas the effect of MCM3 in Chinese patients with HCC remains unclear. Furthermore, the aforementioned studies did not reveal an association between MCM3 and HCC clinical features or the diagnostic ability of MCM3 in combination with its interacting proteins. In the present study, MCM3 mRNA and protein expression was found to be higher in HCC tissues than in adjacent tissues. Analysis of MCM3 using the TCGA database revealed that high MCM3 expression was associated with high AFP levels and an advanced E-S grade. Furthermore, high MCM3 expression was associated with poor OS and RFS, suggesting that high MCM3 expression levels may be predictive of a poor OS and RFS in HCC. Furthermore, in HCC tissues collected from a cohort of Chinese patients, high mRNA expression levels of MCM3 were associated with HCC invasion. Previous studies have suggested that tumor invasion is associated with poor outcomes in numerous types of cancer, including HCC (28-32). The present study suggested that MCM3 may be a novel prognostic marker of HCC and that high MCM3 expression may be associated with poor disease outcomes. AFP is a common diagnostic marker for patients with HCC, which is also used to evaluate tumor recurrence (17). A previous study demonstrated that high AFP expression was related to the poor prognosis of patients, and the higher the expression of serum AFP, the worse the prognosis of patients (17). However, there was no association identified between MCM3 expression levels and AFP levels (or E-S grade) in Chinese patients with HCC. On the one hand, TCGA mainly consists of data from Caucasian populations, whereas the current study included $\mathrm{HCC}$ tissues from a Chinese 


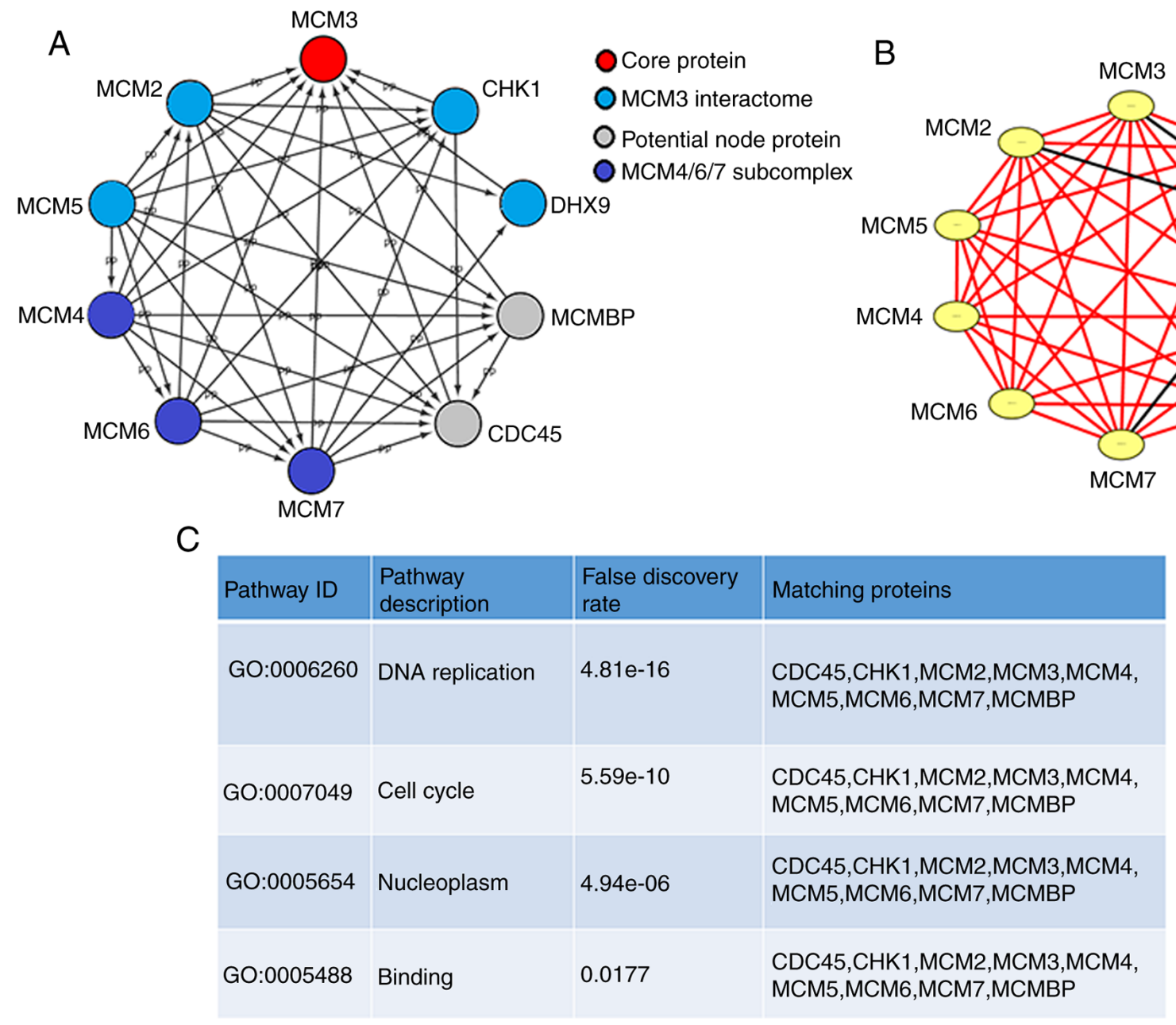

Figure 3. PPI network and core module of MCM3. (A) PPI network of MCM3 (B) Core module for MCM3 and its interaction partners. Yellow nodes represent proteins from the same module. Pink nodes represent proteins not belonging to a specific module. (C) Enrichment and pathway analysis of the module. PPI, protein-protein interaction; MCM, minichromosome maintenance complex component; CHK1, checkpoint kinase 1; DHX9, DEAH (Asp-Glu-Ala-His) box helicase 9; CDC45, cell division control protein 45 homolog; MCMBP, minichromosome maintenance complex binding protein; GO, Gene Ontology.

population. Hence, ethnic diversity may be responsible for the observed difference. However, there was a considerable difference in the sample size between the collected HCC samples and samples from TCGA, which may also be a possible reason why there was no association between MCM3 expression and AFP levels in the current cohort. Therefore, further analysis including more HCC samples from Chinese patients and additional ethnicities would help to elucidate the discrepancy in the outcome observed between TCGA and the analyzed cohort of Chinese patients. Furthermore, it would be helpful to understand the association between the expression levels of MCM3 and AFP levels.

The GO and KEGG enrichment analysis revealed that MCM3 and its interacting proteins, including DHX9, CHK1 and MCM components (MCM2/5), were associated with 'DNA replication' and 'cell cycle'. Interestingly, the MFs showed that they participated in numerous binding processes, indicating that abnormal expression of MCM3 and its interacting proteins may have adverse effects in normal cells, which could be a vital trigger leading to $\mathrm{HCC}$.

The regulation of cell proliferation is fundamental for cell growth and the prevention of cancer. An important step in the regulation of cell proliferation lies in regulating the initiation of DNA synthesis (33). MCM proteins are essential DNA replication factors serving a role in initiating DNA synthesis once per cell cycle (34). Altered levels of MCM proteins have been detected in malignant human cancer cells, such as melanoma, prostate cancer, cervical squamous cell carcinoma, salivary gland tumors, and pre-cancerous cells undergoing malignant transformation (34). DNA replication triggered by the activity of the MCM2-7 complex consists of the MCM4/6/7 core complex and the loosely associated MCM2 and MCM3/5 (25). Previous studies have indicated that both the MCM2 protein and MCM3/5 complex inhibit MCM4/6/7 helicase activity by disassembling the MCM4/6/7 hexamer into the MCM2/4/6/7 and MCM3/4/5/6/7 complexes, respectively $(25,35)$. The inhibitory role of MCM3 may be based on the simple mechanism that free MCM3 and/or MCM3/5 decrease the amount of their adjacent MCM partners, which is associated with the presence of 2-3 times higher MCM3 levels than those of any of the other five MCM proteins (35). Furthermore, MCM3/5 has a direct role in transcription, and increased levels of MCM5 are associated with the activation of transcription (36).

In the present study, MCM2, MCM3 and MCM5 levels were identified to be elevated in HCC. Juríková et al (36) 
Table V. GO and KEGG pathway enrichment analyses of MCM3 and its node genes.

\begin{tabular}{|c|c|c|c|c|}
\hline Category & Pathway ID & Pathway description & $\begin{array}{l}\text { Gene } \\
\text { count }\end{array}$ & Matching proteins \\
\hline Biological process & GO:0006260 & DNA replication & 10 & $\begin{array}{l}\text { CDC } 45, \text { CHK1, DHX9, MCM2, MCM3, } \\
\text { MCM4, MCM5, MCM6, MCM7, MCMBP }\end{array}$ \\
\hline Biological process & GO:0006270 & DNA replication initiation & 7 & $\begin{array}{l}\text { CDC } 45, \text { MCM } 2, \text { MCM3, MCM4, MCM5, } \\
\text { MCM6, MCM } 7\end{array}$ \\
\hline Biological process & GO:0006261 & $\begin{array}{l}\text { DNA-dependent DNA } \\
\text { replication }\end{array}$ & 8 & $\begin{array}{l}\text { CDC } 45, \text { MCM2, MCM3, MCM4, MCM5, } \\
\text { MCM6, MCM7, MCMBP }\end{array}$ \\
\hline Biological process & GO:0000082 & $\begin{array}{l}\text { G1/S transition of mitotic cell } \\
\text { cycle }\end{array}$ & 7 & $\begin{array}{l}\text { CDC } 45, \text { MCM2, MCM3, MCM4, MCM5, } \\
\text { MCM6, MCM7 }\end{array}$ \\
\hline Biological process & GO:0032508 & DNA duplex unwinding & 6 & $\begin{array}{l}\text { CDC } 45, \text { DHX9, MCM2, MCM4, MCM6, } \\
\text { MCM7 }\end{array}$ \\
\hline Biological process & GO:0006268 & $\begin{array}{l}\text { DNA unwinding involved in } \\
\text { DNA replication }\end{array}$ & 4 & MCM2, MCM4, MCM6, MCM7 \\
\hline Biological process & GO:0007049 & Cell cycle & 9 & $\begin{array}{l}\text { CDC } 45, \text { CHK1, MCM2, MCM3, MCM4, } \\
\text { MCM5, MCM6, MCM7, MCMBP }\end{array}$ \\
\hline Biological process & GO:0022402 & Cell cycle process & 8 & $\begin{array}{l}\text { CDC } 45, \text { MCM2, MCM3, MCM4, MCM5, } \\
\text { MCM6, MCM7, MCMBP }\end{array}$ \\
\hline Biological process & GO:0051276 & Chromosome organization & 8 & $\begin{array}{l}\text { CDC } 45, \text { CHK1, DHX9, MCM2, MCM4, } \\
\text { MCM6, MCM7, MCMBP }\end{array}$ \\
\hline Biological process & GO:0033044 & $\begin{array}{l}\text { Regulation of chromosome } \\
\text { organization }\end{array}$ & 3 & CDC45, CHK1, MCM2 \\
\hline Biological process & GO:0006282 & Regulation of DNA repair & 2 & CHK1, DHX9 \\
\hline Biological process & GO:0060968 & Regulation of gene silencing & 2 & CDC45, DHX9 \\
\hline Biological process & GO:0031570 & DNA integrity checkpoint & 2 & CDC45, CHK1 \\
\hline Biological process & GO: 1902275 & $\begin{array}{l}\text { Regulation of chromatin } \\
\text { organization }\end{array}$ & 2 & CDC45, CHK1 \\
\hline Cell component & GO:0042555 & MCM complex & 6 & $\begin{array}{l}\text { MCM2, MCM3, MCM4, MCM5, MCM6, } \\
\text { MCM7 }\end{array}$ \\
\hline Cell component & GO:0 & Nucle & 10 & $\begin{array}{l}\text { CDC45, CHK1, DHX9, MCM2, MCM3, } \\
\text { MCM4, MCM5, MCM6, MCM7, MCMBP }\end{array}$ \\
\hline Cell component & GO:0044427 & Chromosomal part & 7 & $\begin{array}{l}\text { CDC } 45, \text { CHK1, DHX9, MCM2, MCM3, } \\
\text { MCM7, MCMBP }\end{array}$ \\
\hline Cell component & GO:0000228 & Nuclear chromosome & 6 & $\begin{array}{l}\text { CDC } 45, \text { CHK1, DHX9, MCM2, MCM3, } \\
\text { MCMBP }\end{array}$ \\
\hline Cell component & GO:0000785 & Chromatin & 5 & CHK1, DHX9, MCM2, MCM7, MCMBP \\
\hline Cell component & GO:0044454 & Nuclear chromosome part & 5 & CDC45, DHX9, MCM2, MCM3, MCMBP \\
\hline Cell component & GO:0032991 & Protein-containing complex & 9 & $\begin{array}{l}\text { CDC45, CHK1, DHX9, MCM2, MCM3, } \\
\text { MCM4, MCM5, MCM6, MCM7 }\end{array}$ \\
\hline Cell component & GO:0005813 & Centrosome & 4 & CDC45, CHK1, DHX9, MCM3 \\
\hline Cell component & GO:0043596 & Nuclear replication fork & 2 & CDC45, MCM3 \\
\hline Cell component & GO:0015630 & Microtubule cytoskeleton & 5 & CDC45, CHK1, DHX9, MCM2, MCM3 \\
\hline Cell component & GO:0032993 & Protein-DNA complex & 2 & CDC45, MCM3 \\
\hline Cell component & GO:0000790 & Nuclear chromatin & 2 & DHX9, MCMBP \\
\hline Molecular function & GO:0004386 & Helicase activity & 8 & $\begin{array}{l}\text { CDC45, DHX9, MCM2, MCM3, MCM4, } \\
\text { MCM5, MCM6, MCM7 }\end{array}$ \\
\hline Molecular function & GO:0003678 & DNA helicase activity & 5 & CDC45, DHX9, MCM4, MCM6, MCM7 \\
\hline Molecular function & GO:0003688 & DNA replication origin binding & 4 & CDC45, DHX9, MCM2, MCM5 \\
\hline Molecular function & GO:0003697 & Single-stranded DNA binding & 5 & CDC45, DHX9, MCM4, MCM6, MCM7 \\
\hline Molecular function & GO:0005524 & ATP binding & 8 & $\begin{array}{l}\text { CHK1, DHX9, MCM2, MCM3, MCM4, } \\
\text { MCM5, MCM6, MCM7 }\end{array}$ \\
\hline Molecular function & GO:0003677 & DNA binding & 8 & $\begin{array}{l}\text { CDC } 45, \text { DHX9, MCM2, MCM3, MCM4, } \\
\text { MCM5, MCM6, MCM7 }\end{array}$ \\
\hline
\end{tabular}


Table V. Continued.

\begin{tabular}{|c|c|c|c|c|}
\hline Category & Pathway ID & Pathway description & $\begin{array}{l}\text { Gene } \\
\text { count }\end{array}$ & Matching proteins \\
\hline Molecular function & GO:0043138 & $3^{\prime} \rightarrow 5^{\prime}$ DNA helicase activity & 2 & CDC45, DHX9 \\
\hline Molecular function & GO:1901363 & Heterocyclic compound binding & 9 & $\begin{array}{l}\text { CDC45, CHK1, DHX9, MCM2, MCM3, } \\
\text { MCM4, MCM5, MCM6, MCM7 }\end{array}$ \\
\hline Molecular function & GO:0097159 & $\begin{array}{l}\text { Organic cyclic compound } \\
\text { binding }\end{array}$ & 9 & $\begin{array}{l}\text { CDC45, CHK1, DHX9, MCM2, MCM3, } \\
\text { MCM4, MCM5, MCM6, MCM7 }\end{array}$ \\
\hline Molecular function & GO:0003824 & Catalytic activity & 9 & $\begin{array}{l}\text { CDC45, CHK1, DHX9, MCM2, MCM3, } \\
\text { MCM4, MCM5, MCM6, MCM7 }\end{array}$ \\
\hline Molecular function & GO:0003682 & Chromatin binding & 3 & CDC45, DHX9, MCMBP \\
\hline Molecular function & GO:0005488 & Binding & 10 & $\begin{array}{l}\text { CDC45, CHK1, DHX9, MCM2, MCM3, } \\
\text { MCM4, MCM5, MCM6, MCM7, MCMBP }\end{array}$ \\
\hline KEGG & hsa04110 & Cell cycle & 8 & $\begin{array}{l}\text { CDC } 45, \text { CHK1, MCM2, MCM3, MCM4, } \\
\text { MCM5, MCM6, MCM7 }\end{array}$ \\
\hline KEGG & hsa03030 & DNA replication & 6 & $\begin{array}{l}\text { MCM2, MCM3, MCM4, MCM5, MCM6, } \\
\text { MCM7 }\end{array}$ \\
\hline
\end{tabular}

GO, Gene Ontology; KEGG, Kyoto Encyclopedia of Genes and Genomes; MCM, minichromosome maintenance complex component; CDC45, cell division control protein 45 homolog; CHK1, checkpoint kinase 1; DHX9, DEAH (Asp-Glu-Ala-His) box helicase 9; MCMBP, minichromosome maintenance complex binding protein.

Table VI. Sensitivity and specificity of hepatocellular carcinoma diagnosis by analyzing the expression of MCM3 and its interacting proteins.

\begin{tabular}{lccc}
\hline Diagnostic marker & AUC & Sensitivity, $\%$ & Specificity, $\%$ \\
\hline MCM2 & 0.930 & 85.95 & 88 \\
MCM3 & 0.932 & 85.40 & 92 \\
MCM5 & 0.895 & 74.93 & 92 \\
CHK1 & 0.883 & 75.76 & 90 \\
DHX9 & 0.727 & 52.34 & 96 \\
Model 1 (CHK1 and MCM3) & 0.975 & 88.15 & 100 \\
Model 2 (DHX9 and MCM3) & 0.967 & 99.17 & 94 \\
Model 3 (MCM2, MCM3 and MCM5) $^{\mathrm{c}}$ & 0.989 & 98.35 & 94 \\
\hline
\end{tabular}

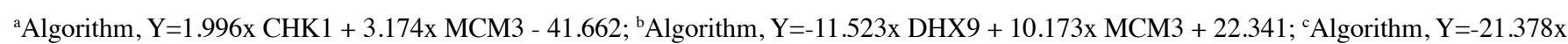
MCM5 + 3.841 x MCM3 + 14.988x MCM2 + 49.305. MCM, minichromosome maintenance complex component; CHK1, checkpoint kinase 1; DHX9, DEAH (Asp-Glu-Ala-His) box helicase 9; AUC, area under the curve.

suggested that the expression levels of all MCM proteins are associated with each other in disease prognosis and that co-overexpression of the six MCM proteins is higher in breast cancer compared with control samples. Depletion or mutation of one MCM protein has been revealed to decrease the levels of all other MCM proteins (35). The present results indicated that MCM2, MCM3 and MCM5 expression was increased in HCC. Furthermore, high levels of MCM2 and MCM3 were associated with poor OS and RFS. Hua et al (37) reported that elevated MCM2 and MCM3 mRNA levels are associated with poor outcomes in patients with glioma and these proteins could be clinically useful molecular prognostic markers for glioma. Similarly, research has indicated that MCM2 and MCM3 act as oncogenes in osteosarcoma by conducting in vitro experiments (38). However, in $\mathrm{HCC}$, the role and the underlying mechanism of MCM2, MCM3 and MCM5 remain unclear.

DHX9 is an enzyme that catalyzes the ATP-dependent unwinding of double-stranded RNA and DNA-RNA complexes. DHX9 mainly binds to inverted-repeat Alu elements and inhibits the production of circular RNAs (39). Abnormal DHX9 expression has been detected in different tumors, including HCC, colorectal cancer, lung cancer, osteosarcoma, breast cancer and prostate cancer (38-41). A previous study indicated that DHX9 interacts with MCM2 and MCM3 in osteosarcoma cells (38). In addition, the decreased growth of osteosarcoma cells due to MCM2 or MCM3 knockdown is reversed by DHX9 overexpression, indicating that MCM2 

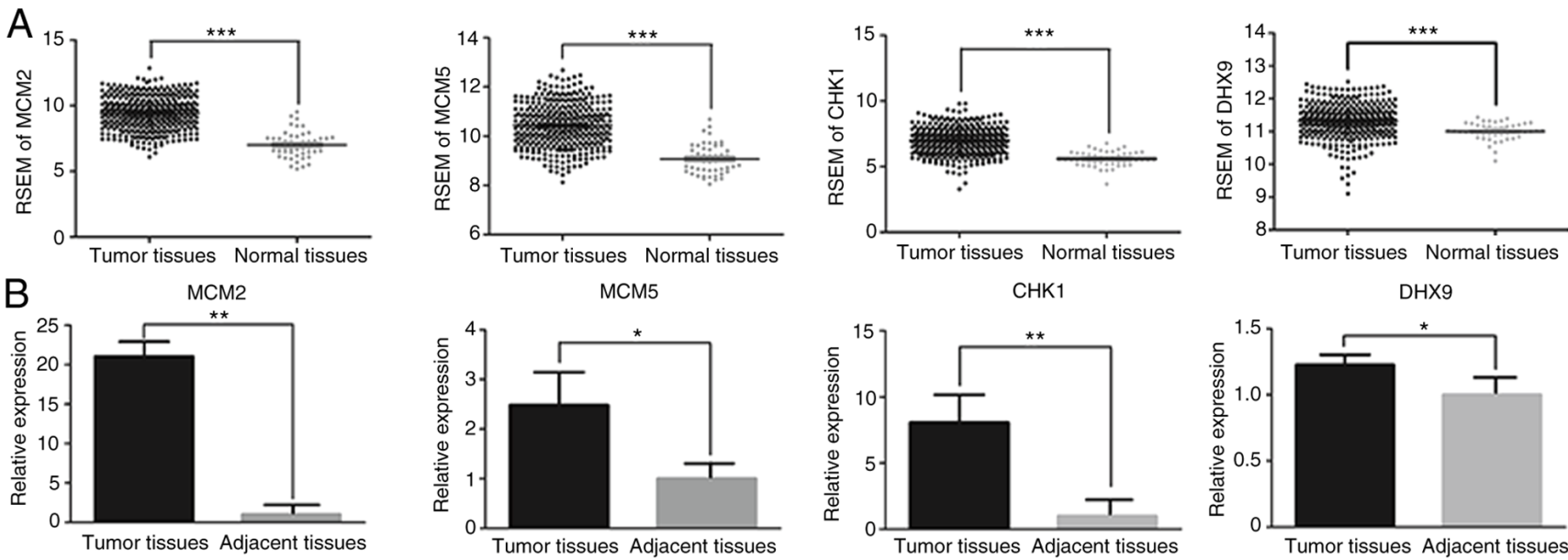

MCM5

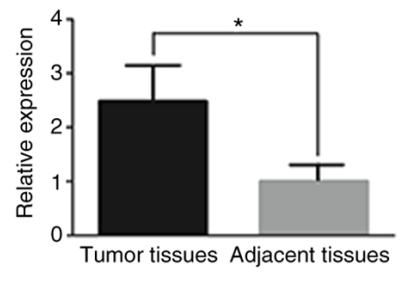

CHK1

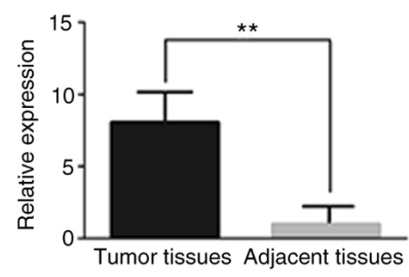

DHX9
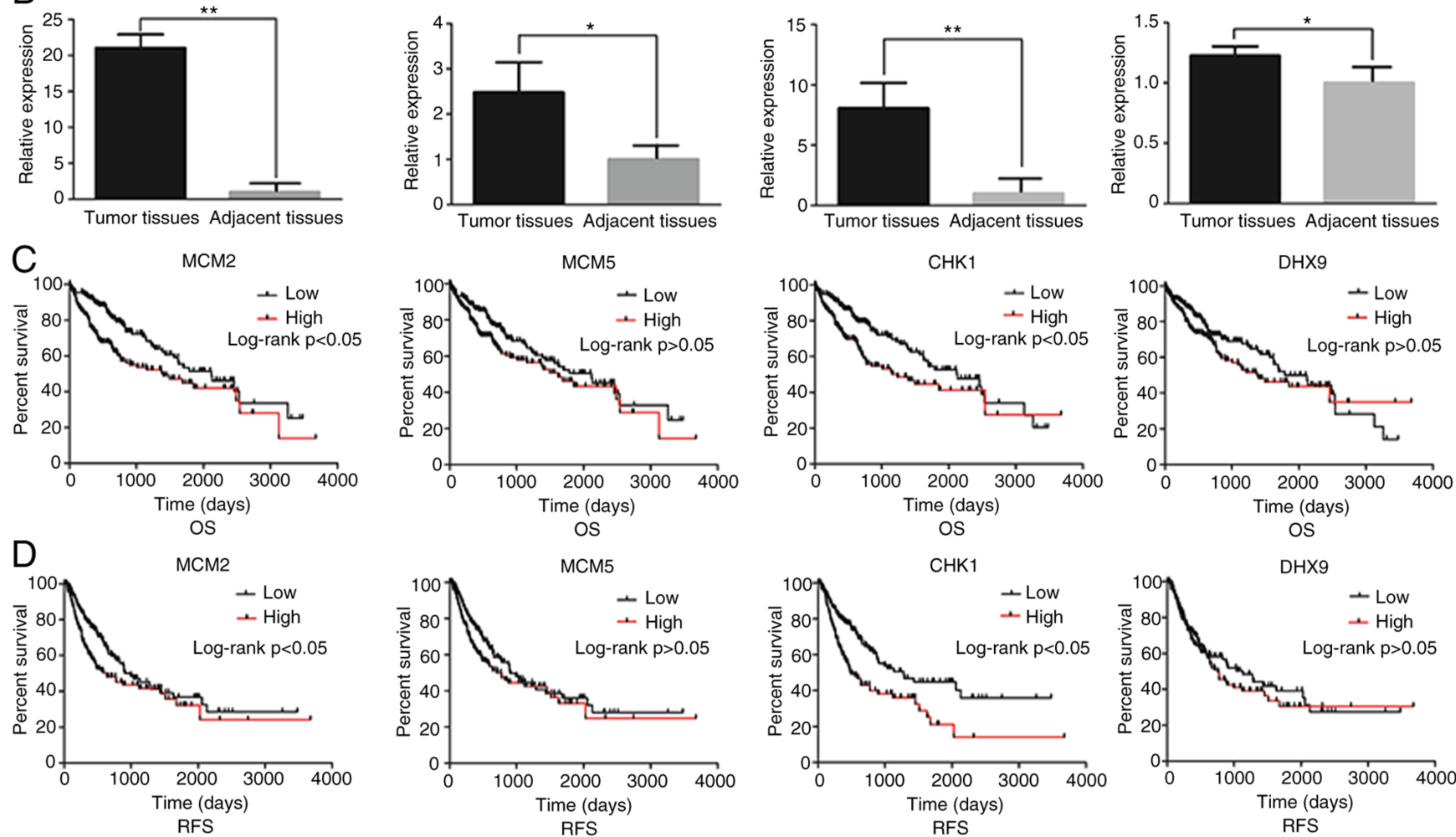

os

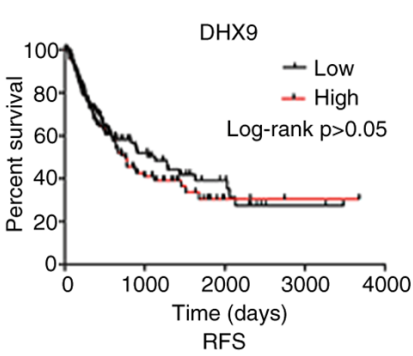

Figure 4. Impact of MCM3 interacting proteins in HCC. (A) mRNA expression of MCM2, MCM5, CHK1 and DHX9 in HCC tissues and normal liver tissues from The Cancer Genome Atlas database. mRNA expression was normalized by RSEM. (B) Relative mRNA expression levels of MCM2, MCM5, CHK1 and DHX9 in HCC and adjacent tissues from the patients recruited in the present study. (C) OS curves and (D) RFS curves for HCC samples expressing high and low levels of the indicated MCM3 interacting proteins. MCM, minichromosome maintenance complex component; CHK1, checkpoint kinase 1; DHX9, DEAH (Asp-Glu-Ala-His) box helicase 9; HCC, hepatocellular carcinoma; RSEM, RNA-Seq by Expectation-Maximization; OS, overall survival; RFS, recurrence-free survival. ${ }^{*} \mathrm{P}<0.05,{ }^{* *} \mathrm{P}<0.01,{ }^{* * *} \mathrm{P}<0.001$.

A

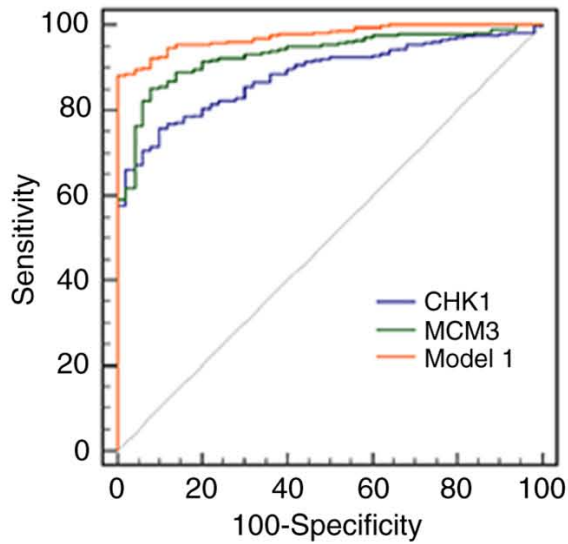

B

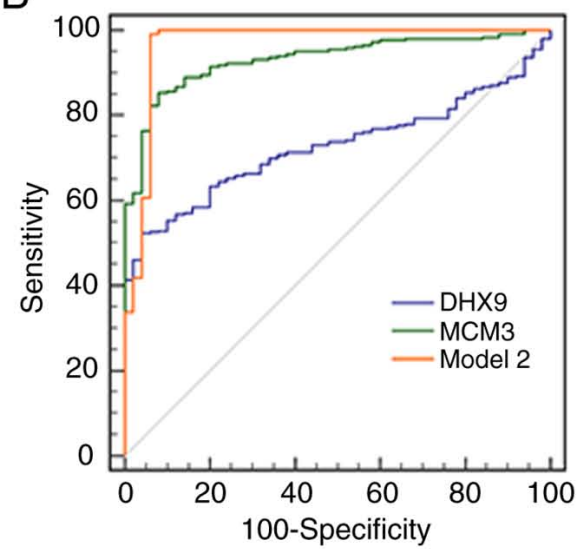

C

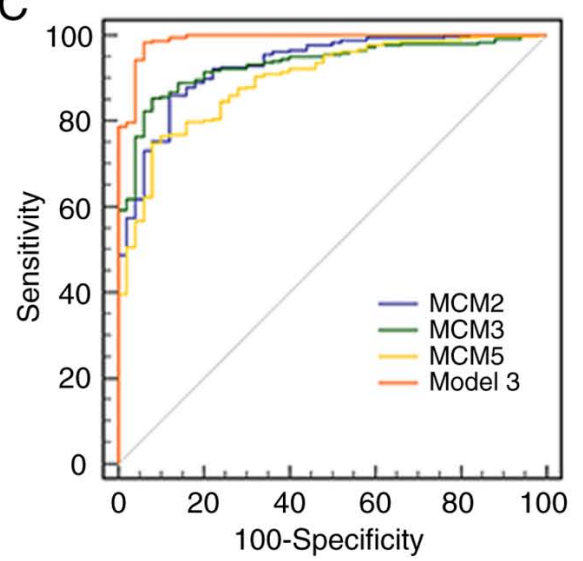

Figure 5. ROC curves of different genes and combined models for diagnosis of hepatocellular carcinoma. The orange solid ROC curve represents models with combined proteins. (A) ROC curves of CHK1, MCM3 and model 1. Model 1 was the combination of CHK1 and MCM3. P $<0.05$ for AUC of Model 1 vs. CHK1 or MCM3. (B) ROC curves of DHX9, MCM3 and model 2. Model 2 was the combination of DHX9 and MCM3. P<0.05 for AUC of Model 2 vs. DHX9 or MCM3. (C) ROC curves of MCM2, MCM3, MCM5 and model 3. Model 3 was the combination of MCM2, MCM3 and MCM5. P<0.05 for AUC of Model 3 vs. MCM2, MCM3 or MCM5. ROC, receiver operating characteristic; CHK1, checkpoint kinase 1; MCM, minichromosome maintenance complex component; AUC, area under the curve; DHX9, DEAH (Asp-Glu-Ala-His) box helicase 9. 
and MCM3 activity is DHX9-dependent (38). In the present study, DHX9 mRNA levels were found to be increased in HCC tissues compared with in adjacent tissues. It has been reported that MCM2 and MCM3 function through DHX9 and that the MCM2/3-DHX9 axis may mediate transcription, translation and DNA replication in osteosarcoma $(42,43)$. The findings of the present study revealed that DHX9 may coordinate with $\mathrm{MCM} 2 \mathrm{MCM} 3$ in $\mathrm{HCC}$, suggesting that targeting the MCM2/3-DHX9 axis may be a feasible and effective strategy for HCC treatment (38). However, the exact role of the MCM2/3-DHX9 axis in proliferation of $\mathrm{HCC}$ requires further study.

CHK1 is a central protein involved in the DNA damage response (DDR), particularly responding to damage caused by cytotoxic agents. Increased CHK1 expression has been identified in a variety of human tumors, including breast, colon, gastric and nasopharyngeal cancer (44). In the present study, CHK1 was found to be overexpressed in HCC, which is consistent with previous studies $(45,46)$. Han et al (47), suggested that CHK1 serves a fundamental role in the phosphorylation of MCM3 at Ser-205 under normal cell growth conditions. MCM3 phosphorylation by CHK1 negatively inhibits normal DNA replication, whereas CHK1 inhibition leads to increased DNA replication (47). The present study demonstrated that CHK1 and MCM3 were upregulated in HCC, and high CHK1 expression was associated with poor OS and RFS. As higher CHK1 expression is associated with an enhanced ability to respond to DNA damage, thereby promoting DNA replication (44), HCC cells may display increased proliferation and improved resistance to DNA damage compared with normal cells. A previous study has also suggested that malignant tumor cells can survive severe DNA replication stress, which results in the DDR (48). CHK1 could phosphorylate multiple targets in the DDR, such as MCM3 and p53 $(47,48)$.

ROC curves were constructed based on the TCGA data. The AUC for MCM3 was larger than that for MCM2, MCM3, CHK1 and DHX9, suggesting that MCM3 may be a valuable marker in the diagnosis of HCC. The three combined models displayed enhanced HCC diagnostic ability compared with MCM3 alone. At optimal cut-offs with the maximal Youden index, model 1 had the highest specificity, model 2 had the highest sensitivity and the AUC of model 3 was the largest. The results of the present study suggest that the properties of multi-gene HCC diagnosis are affected by the genes included in the combined model. MCM3 and its combined models had higher sensitivities and specificities than existing HCC diagnostic markers, such as glypican-3 and AFP, which had pooled sensitivities and specificities of 0.55 (95\% CI, 0.52-0.58) and 0.58 (95\% CI, 0.54-0.61), and 0.54 (95\% CI, 0.51-0.57) and 0.83 (95\% CI, 0.80-0.85), respectively (49).

In conclusion, higher MCM3 expression levels were identified in HCC than in normal liver tissues, and high MCM3 expression was associated with high AFP levels and advanced E-S grade. Additionally, high MCM3 expression was associated with poor OS and RFS. Furthermore, in HCC tissues collected from Chinese patients, high MCM3 expression was associated with HCC invasion. Functional and pathway enrichment analysis revealed that MCM3 and its interacting proteins were primarily involved in 'DNA replication', 'cell cycle' and in the binding process with numerous substrates (DNA/protein/organic compounds). Similarly, TCGA and RT-qPCR analysis demonstrated that the expression levels of MCM3 interactome proteins (MCM2/5, CHK1 and DHX9) were increased in HCC. An algorithm combining the ROCs of MCM3 and the other interaction partners was more specific and sensitive for the diagnosis HCC than other conventional HCC diagnostic markers. The present study revealed that MCM3 and its interacting proteins may be potential novel diagnostic markers for HCC.

\section{Acknowledgements}

The authors would like to thank Professor Guandou Yuan (Division of Hepatobiliary Surgery, The First Affiliated Hospital of Guangxi Medical University, Nanning, China) for his help in revising the manuscript.

\section{Funding}

The present study was supported by The National Nature Science Foundation of China (grant nos. 81660497 and 81660460), The Natural Science Foundation of Guangxi (grant nos. GuikeAB17195006, 2016GXNSFDA380010 and 2016GXNSFBA380016) and the Students' Platform for Innovation and Entrepreneurship Training Program (grant no. 2018118).

\section{Availability of data and materials}

The datasets used and/or analyzed during the present study are available from the corresponding author on reasonable request.

\section{Authors' contributions}

HTL, XW, BW, ZQL and XLY contributed to the conception and design of the study, analysis of the data, interpretation of the results and the writing of the manuscript. WXJ, XW, HTL, YZX, JYL, MNS, SXC, NFM and DZ conducted the experiments and contributed to the acquisition of data. XW, WPZ, JQ, PL and QLZ analyzed the data. XLY reviewed and edited the manuscript. All authors read and approved the final manuscript.

\section{Ethics approval and consent to participate}

This research project was approved by the Ethics and Human Subjects Committee (EHSC) of Guilin Medical University and conformed to the provisions of the Declaration of Helsinki. Informed consent was obtained from each patient included in the present study.

\section{Patient consent for publication}

Not applicable.

\section{Competing interests}

The authors declare that they have no competing interests. 


\section{References}

1. Maiorano D, Lutzmann M and Mechali M: MCM proteins and DNA replication. Curr Opin Cell Biol 18: 130-136, 2006.

2. Forsburg SL: Eukaryotic MCM proteins: Beyond replication initiation. Microbiol Mol Biol Rev 68: 109-131, 2004.

3. Lee JK and Hurwitz J: Isolation and characterization of various complexes of the minichromosome maintenance proteins of Schizosaccharomyces pombe. J Biol Chem 275: 18871-18878, 2000.

4. Takei $\mathrm{Y}$ and Tsujimoto G: Identification of a novel MCM3-associated protein that facilitates MCM3 nuclear localization. J Biol Chem 273: 22177-22180, 1998

5. Stewart PA, Khamis ZI, Zhau HE, Duan P, Li Q, Chung LWK and Sang QA: Upregulation of minichromosome maintenance complex component 3 during epithelial-to-mesenchymal transition in human prostate cancer. Oncotarget 8: 39209-39217, 2017.

6. Mulvaney KM, Matson JP, Siesser PF, Tamir TY, Goldfarb D, Jacobs TM, Cloer EW, Harrison JS, Vaziri C, Cook JG and Major MB: Identification and characterization of MCM3 as a Kelch-like ECH-associated protein 1 (KEAP1) substrate. J Biol Chem 291: 23719-23733, 2016

7. Guo J, Ma Z, Ma Q, Wu Z, Fan P, Zhou X, Chen L, Zhou S, Goltzman D, Miao D and Wu E: 1, 25(OH)2D3 inhibits hepatocellular carcinoma development through reducing secretion of inflammatory cytokines from immunocytes. Curr Med Chem 20 : 4131-4141, 2013.

8. Liu D, Staveley-O'Carroll KF and Li G: Immune-based therapy clinical trials in hepatocellular carcinoma. J Clin Cell Immunol 6: $376,2015$.

9. Kim HS and El-Serag HB: The epidemiology of hepatocellular carcinoma in the USA. Curr Gastroenterol Rep 21: 17, 2019.

10. Cui J, Zhou XD, Liu YK, Tang ZY and Zile MH: Abnormal beta-catenin gene expression with invasiveness of primary hepatocellular carcinoma in China. World J Gastroenterol 7: 542-546, 2001.

11. Ishibashi Y, Kinugasa T, Akagi Y, Ohchi T, Gotanda Y, Tanaka N, Fujino S, Yuge K, Kibe S, Yoshida N, et al: Minichromosome maintenance protein 7 is a risk factor for recurrence in patients with Dukes C colorectal cancer. Anticancer Res 34: 4569-4575, 2014.

12. Kato K, Toki T, Shimizu M, Shiozawa T, Fujii S, Nikaido T and Konishi I: Expression of replication-licensing factors MCM2 and MCM3 in normal, hyperplastic, and carcinomatous endometrium: Correlation with expression of $\mathrm{Ki}-67$ and estrogen and progesterone receptors. Int J Gynecol Pathol 22: 334-340, 2003.

13. Lau KM, Chan QK, Pang JC, Li KK, Yeung WW, Chung NY, Lui PC, Tam YS, Li HM, Zhou L, et al: Minichromosome maintenance proteins 2, 3 and 7 in medulloblastoma: Overexpression and involvement in regulation of cell migration and invasion. Oncogene 29: 5475-5489, 2010.

14. Chevalier S and Blow JJ: Cell cycle control of replication initiation in eukaryotes. Curr Opin Cell Biol 8: 815-821, 1996.

15. Carreon-Burciaga RG, Gonzalez-Gonzalez R, Molina-Frechero N and Bologna-Molina R: Immunoexpression of Ki-67, MCM2, and MCM3 in ameloblastoma and ameloblastic carcinoma and their correlations with clinical and histopathological patterns. Dis Markers 2015: 683087, 2015.

16. Zhou L, Wang SB, Chen SG, Qu Q and Rui JA: Prognostic value of ALT, AST, and AAR in hepatocellular carcinoma with B-Type hepatitis-associated cirrhosis after radical hepatectomy. Clin Lab 64: 1739-1747, 2018

17. Bi X, Yan T, Zhao H, Zhao J, Li Z, Huang Z, Zhou J and Cai J: Correlation of alpha fetoprotein with the prognosis of hepatocellular carcinoma after hepatectomy in an ethnic Chinese population. Zhonghua Yi Xue Za Zhi 94: 2645-2649, 2014 (In Chinese).

18. Zhou J, Sun HC, Wang Z, Cong WM, Wang JH, Zeng MS, Yang JM, Bie P, Liu LX, Wen TF, et al: Guidelines for diagnosis and treatment of primary liver cancer in China (2017 edition). Liver Cancer 7: 235-260, 2018

19. Zhou L, Rui JA, Zhou WX, Wang SB, Chen SG and Qu Q Edmondson-Steiner grade: A crucial predictor of recurrence and survival in hepatocellular carcinoma without microvascular invasio. Pathol Res Pract 213: 824-830, 2017.

20. Livak KJ and Schmittgen TD: Analysis of relative gene expression data using real-time quantitative PCR and the 2(-Delta Delta $\mathrm{C}(\mathrm{T}))$ method. Methods 25: 402-408, 2001
21. Shi K, Wang SL, Shen B, Yu FQ, Weng DF and Lin JH Clinicopathological and prognostic values of fibronectin and integrin alphavbeta3 expression in primary osteosarcoma. World J Surg Oncol 17: 23, 2019.

22. Bader $G$ and Hogue $C$ : An automated method for finding molecular complexes in large protein interaction networks. BMC Bioinformatics 4: 2, 2003

23. Cai C, Wang W and Tu Z: Aberrantly DNA methylated-differentially expressed genes and pathways in hepatocellular carcinoma. J Cancer 10: 355-366, 2019.

24. Korner T, Kropf J, Kosche B, Kristahl H, Jaspersen D and Gressner AM: Improvement of prognostic power of the Child-Pugh classification of liver cirrhosis by hyaluronan. J Hepatol 39: 947-953, 2003.

25. Stead BE, Sorbara CD, Brandl CJ and Davey MJ: ATP binding and hydrolysis by $\mathrm{Mcm} 2$ regulate DNA binding by $\mathrm{Mcm}$ complexes. J Mol Biol 391: 301-313, 2009.

26. Zhuang L, Yang Z and Meng Z: Upregulation of BUB1B, CCNB1, CDC7, CDC20, and MCM3 in tumor tissues predicted worse overall survival and disease-Free survival in hepatocellular carcinoma patients. Biomed Res Int 2018: 7897346, 2018.

27. Liao X, Liu X, Yang C, Wang X, Yu T, Han C, Huang K, Zhu G, $\mathrm{Su} \mathrm{H}$, Qin W, et al: Distinct diagnostic and prognostic values of minichromosome maintenance gene expression in patients with hepatocellular carcinoma. J Cancer 9: 2357-2373, 2018.

28. Liu Y, Zhang Y, Zhao Y, Gao D, Xing J and Liu H: High PARP-1 expression is associated with tumor invasion and poor prognosis in gastric cancer. Oncol Lett 12: 3825-3835, 2016.

29. Chatterjee D, Rashid A, Wang H, Katz MH, Wolff RA, Varadhachary GR, Lee JE, Pisters PW, Gomez HF, Abbruzzese JL, et al: Tumor invasion of muscular vessels predicts poor prognosis in patients with pancreatic ductal adenocarcinoma who have received neoadjuvant therapy and pancreaticoduodenectomy. Am J Surg Pathol 36: 552-559, 2012.

30. Hong SM, Pawlik TM, Cho H, Aggarwal B, Goggins M, Hruban RH and Anders RA: Depth of tumor invasion better predicts prognosis than the current American Joint Committee on Cancer T classification for distal bile duct carcinoma. Surgery 146: 250-257, 2009.

31. Bi XW, Zhang WW, Li ZM, Huang JJ, Xia Y, Sun P, Wang Y and Jiang WQ: The extent of local tumor invasion predicts prognosis in stage IE nasal natural killer/T-cell lymphoma: A novel T staging system for risk stratification. Ann Hematol 94: $1515-1524,2015$

32. Fan J, Tang ZY, Wu ZQ, Zhou J, Zhou XD, Ma ZC, Qin LX, Qiu SJ, Yu Y and Huang C: The effects of portal vein microscopic and macroscopic tumor thrombi on post-operation patients with hepatocellular carcinoma. Zhonghua Wai Ke Za Zhi 43: 433-435, 2005 (In Chinese).

33. Ryu S and Driever W: Minichromosome maintenance proteins as markers for proliferation zones during embryogenesis. Cell Cycle 5: 1140-1142, 2006.

34. Lei M: The MCM complex: Its role in DNA replication and implications for cancer therapy. Curr Cancer Drug Targets 5: 365-380, 2005

35. Chuang CH, Yang D, Bai G, Freeland A, Pruitt SC and Schimenti JC: Post-transcriptional homeostasis and regulation of MCM2-7 in mammalian cells. Nucleic Acids Res 40: 4914-4924, 2012.

36. Juríková M, Danihel L, Polák Š and Varga I: Ki67, PCNA, and MCM proteins: Markers of proliferation in the diagnosis of breast cancer. Acta Histochem 118: 544-552, 2016.

37. Hua C, Zhao G, Li Y and Bie L: Minichromosome Maintenance (MCM) Family as potential diagnostic and prognostic tumor markers for human gliomas. BMC Cancer 14: 526, 2014.

38. Cheng DD, Zhang HZ, Yuan JQ, Li SJ, Yang QC and Fan CY: Minichromosome maintenance protein 2 and 3 promote osteosarcoma progression via DHX9 and predict poor patient prognosis. Oncotarget 8: 26380-26393, 2017.

39. Yu J, Xu QG, Wang ZG, Yang Y, Zhang L, Ma JZ, Sun SH, Yang F and Zhou WP: Circular RNA cSMARCA5 inhibits growth and metastasis in hepatocellular carcinoma. J Hepatol 68: 1214-1227, 2018.

40. Cao S, Sun R, Wang W, Meng X, Zhang Y, Zhang N and Yang S: RNA helicase DHX9 may be a therapeutic target in lung cancer and inhibited by enoxacin. Am J Transl Res 9: 674-682, 2017.

41. Mi J, Ray P, Liu J, Kuan CT, Xu J, Hsu D, Sullenger BA, White RR and Clary BM: In vivo selection against human colorectal cancer xenografts identifies an aptamer that targets RNA helicase protein DHX9. Mol Ther Nucleic Acids 5: e315, 2016. 
42. Lee T, Paquet M, Larsson $\mathrm{O}$ and Pelletier J: Tumor cell survival dependence on the DHX9 DExH-box helicase. Oncogene 35: 5093-5105, 2016.

43. Fidaleo M, Svetoni F, Volpe E, Minana B, Caporossi D and Paronetto MP: Genotoxic stress inhibits Ewing sarcoma cell growth by modulating alternative pre-mRNA processing of the RNA helicase DHX9. Oncotarget 6: 31740-31757, 2015.

44. Zhang Y and Hunter T: Roles of Chk1 in cell biology and cancer therapy. Int J Cancer 134: 1013-1023, 2014.

45. Jin H, Xu G, Zhang Q, Pang Q and Fang M: Synaptotagmin-7 is overexpressed in hepatocellular carcinoma and regulates hepatocellular carcinoma cell proliferation via Chk1-p53 signaling. Onco Targets Ther 10: 4283-4293, 2017.

46. Hong J, Hu K, Yuan Y, Sang Y, Bu Q, Chen G, Yang L, Li B, Huang P, Chen D, et al: CHK1 targets spleen tyrosine kinase (L) for proteolysis in hepatocellular carcinoma. J Clin Invest 122: 2165-2175, 2012.
47. Han X, Mayca Pozo F, Wisotsky JN, Wang B, Jacobberger JW and Zhang Y: Phosphorylation of minichromosome maintenance 3 (MCM3) by checkpoint kinase 1 (Chk1) negatively regulates DNA replication and checkpoint activation. J Biol Chem 290: 12370-12378, 2015.

48. Kitao H, Iimori M, Kataoka Y, Wakasa T, Tokunaga E, Saeki H, Oki E and Maehara Y: DNA replication stress and cancer chemotherapy. Cancer Sci 109: 264-271, 2018.

49. Xu D, Su C, Sun L, Gao Y and Li Y: Performance of serum glypican 3 in diagnosis of hepatocellular carcinoma: A meta-analysis. Ann Hepatol 18: 58-67, 2018.

(i) (9) This work is licensed under a Creative Commons c) ${ }_{\mathrm{EY}} \mathrm{NO}$ NO Attribution-NonCommercial-NoDerivatives 4.0 International (CC BY-NC-ND 4.0) License. 